\title{
Business Intelligence Framework Supporting Non-BI Factors
}

\author{
Muhammad Irfan Rafiq, Abid Farooq, and Muhammad Usman Mirza
}

\begin{abstract}
Despite of advancement in technology and the overwhelming acceptance of BI tools in enterprise world, human-computer interaction during strategic decision making process is still a question mark. This is so because BI-information flow is mainly derived more from data models than by management oriented decision models or knowledge management. Non-BI factors which greatly influence strategic decision making in real world are still overlooked or very vaguely defined.

We describe a BI-Model in context of project upraising which supports non-BI factors concerning to particular business needs to make possible a seamless integration of technology into a logical business intelligence environment. Thus enable modeling management decisions and to map business intelligence, knowledge management, human intellect in traditional BI to develop a Real Business Intelligence. The study also encompasses some of the BI models/frameworks in perspective of non-BI and human-computer interaction. We compare our BI model with traditional BI frameworks, illustrating the importance of non-BI factors and share our experience and the lessons learned in architecting and implementing the framework.
\end{abstract}

Index Terms-BI, business intelligence, real BI, RBI

\section{INTRODUCTION}

Business Intelligence (BI) refers to computer-based techniques used in identifying, digging-out, and analyzing business data, such as analyzing new project requirement for its suitability, sales revenue by products or associated costs and incomes [1].

In 1958 IBM researcher Hans Peter Luhn used the term business intelligence as "The ability to apprehend the interrelationships of presented facts in such a way as to guide action towards a desired goal [2]. Traditional BI technologies include data warehousing technologies such as reporting, ad-hoc querying, and online analytical processing. Whereby, advance BI tools also include data-mining, predictive analysis using rule-based simulations, web services and advanced visualization capabilities [3].

Executives often feel lost when presented with large body of data concerning decision making to accept or reject a new project proposal. Sutcliffe and Weber found that having a lot of facts about a decision situation is less important than having a clear and consistent overview [4].

Manuscript received November 19, 2012; revised February 5, 2013.

The authors are with Department of Computer Sciences, Shaheed Zulfikar Ali Bhutto Institute of Science and Technology (SZABIST), Islamabad, Pakistan (email: faani2@hotmail.com).
Most of the business intelligence tools are based on data warehouse and data analyzing software. As a data driven decision support systems, business intelligence tools focus too much on the data and decision making is based on data analysis reports [5]. When a new situation comes up, traditional business intelligence tools usually dig into the raw data stored in data warehouse and then try to make report through OLAP, data mining and other data analysis software. Such kind of decision making is not efficient enough to make a rational decision while considering a new project or problem.

The underlying objective of this study is to augment the analytical functionality of traditional BI systems by extending traditional BI system on cognitive orientation.

The paper is structured as follows. In Section II we discuss the current state of $\mathrm{BI}$ and importance of non-BI factors in strategic decision making process. The Section III also reveals the missing link in making management centric decision making. Section III gives the overview of architectures of different BI frameworks with non-BI factors perspective and limitations, gaps found thereof. In Section IV we architect the BI framework which supports business specific non-BI factors. In Section V we validate our approach by comparing the proposed model with a few common architectures and we conclude in Section VI.

\section{CURRENT STATE OF BI}

In the last decade or so, the BI has been adopted by major corporations of the world as a tool for informed decision making. A 2009 Gartner paper predicted these developments in business intelligence market [6].

- Because of lack of information, processes, and tools, through 2012, more than 35 per cent of the top 5,000 global companies will regularly fail to make insightful decisions about significant changes in their business and markets [6].

- By 2012, business units will control at least 40 per cent of the total budget for business intelligence [6].

- By 2012, one-third of analytic applications applied to business processes will be delivered through coarsegrained application mashups [6].

A. Modeling of "Management Decisions" a Missing Link in BI"

Gartner declared BI is the top-most priority of many chief information officers. Business leaders and CIOs have recognized $\mathrm{BI}$ as strategic initiative and as instrument in driving business effectiveness and innovation [7]. Despite of mountainous advancement in technology and acceptance 
of $\mathrm{BI}$ as a tool to decision making; strategic decision making is still a scantily defined process. Davenport recently pointed out, ,several companies, despite making million-dollar investments in decision support technologies, still take a very haphazard approach to decision making[8].

This is so, human behavior toward decision making and absence of non-BI factors are not aligned with current BI tools. The use of these factors in decision model can ensure achieving Real Business Intelligence (RBI) through better decision making process.

There are number of non-BI factors involved in every business in enterprise world, processing of which is as important as the processing of operational data needed for right decision making regarding any new initiative. Such non-BI factors may vary from business to business and needs to be identified while architecting the BI applications. Some of the non-BI factors but not limited broadly includes situational awareness, past experiences on a given situation, demographic trends, and socio-economic needs of the customers.

\section{B. Traditional Architecture of BI}

BI system needs to deliver the right information to the decision makers at a right time. The strategic decision making is greatly influenced with the actionable information and non-BI factor. Data has to be processed before it is delivered to the decision makers to opt or make a decision on a given situation [9]. Fig. 1 represents a typical layered view of architecture on which most of the business intelligence systems works.

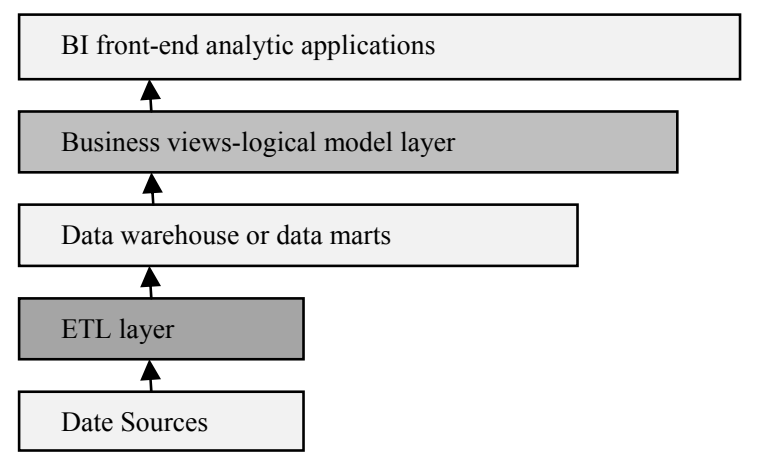

Fig. 1. Represents a typical layered view of architecture on which most of the business intelligence systems works.

\section{RELATED WORK}

B. Azvine et al. discuss the importance of real time business intelligence talk about the emerging technologies which may contribute to realization of real time business intelligence [10].

Current BI system suffers from two bottlenecks in realizing this vision;

Transition from data into information is hindered by shortage of analysts and experts who are required to configure and run analytical software.

The transition from information into action.

In current BI system the information between operational, tactical and strategic layers is broken by manual intervention. The analyst sits between the BI software that operates on the data and the information that is used by management to make decisions. This 'analyst-in-the middle' approach prevents RtBI because the analyst represents a time lag that must be removed.

The authors come up with a vision to seamlessly transform data into information into action. The challenge is to model the manual intervention present in current system and automate both the flow of information from operational to tactical to strategic layer and actions necessary to translate strategic objectives back to operational drivers to affect strategic decision in real time (Fig. 2).

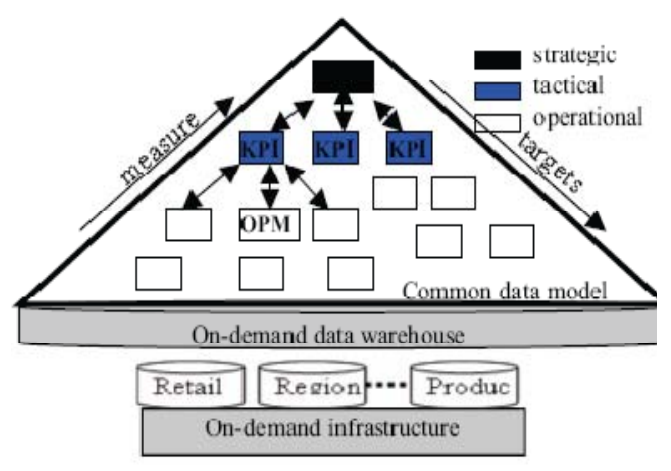

Fig. 2. The vision of RtBI [10]

To remove this manual intervention and automate the analysis requires a high degree of automation so that system may able to select appropriate analysis methods and check against user requirements after automatic application. This is an iterative process and continues until the most suitable decision is found and presented as high level report. If the user decides to act on, the live business process will be changes automatically based on the selected solution. Different techniques for automated analysis like SPIDA, neuro-fuzzy systems, decision optimization and what if analysis is discussed.

In another study Li Niu and Jie Lu et al. talked about the naturalistic decision making (NDM), emerged as a new discipline since 1980's, which has a significant implications for enhancing the functionality of traditional BI system[11]. They presented an exploratory study of web-based cognitive business intelligence systems (CBIS) for naturalistic decision making (Fig. 3).

Cognitive: the notion of cognitive orientation grounds in cognitive psychology, of which situation awareness (SA) and mental model are two important concepts. Decision maker's cognitive ability obsessed by SA and mental models plays a key role for dealing with unstructured problems.

The authors provided an overview of theoretical fundamentals of cognitive business intelligence system:

Situation Awareness (SA): is a cognitive psychology concept which is divided into three levels of mental representations:

Perception: perceiving raw information from the environment.

Comprehension: understanding perceived information.

Projection: predicting the future status of the environment.

The development process of SA is referred as situation assessment.

Mental Model: are commonly referred to as deeply held assumptions and beliefs that enable individuals to make 
inferences and predictions.

CBIS System Architecture: major components of CBIS system have been discussed as:

- Executive: is a user centered information system where the executive is the central component.

- Thinking Support: this module is intended to provide the executive with a set of tools for knowledge management and thinking process support. Think support is made up of following components:
i) Case base
ii) Mental model
iii) Case/mental management

- Knowledge agent: receives the knowledge requests from SA agent (a sub module of SA) and parses, delivers the requests to both case management and mental model.

- Situation assessment: this module is responsible for aiding the executive to develop SA about current decision situation. This module is further categories into three sub-modules:
i) SA agent
ii) Situation Seeking
iii) Situation representation

- Data warehouse sub-system: forms the factual basis on which the decision situation is retrieved, presented and assessed. The subsystem is made up of operational systems, data acquisition, and data storage and data analysis module.

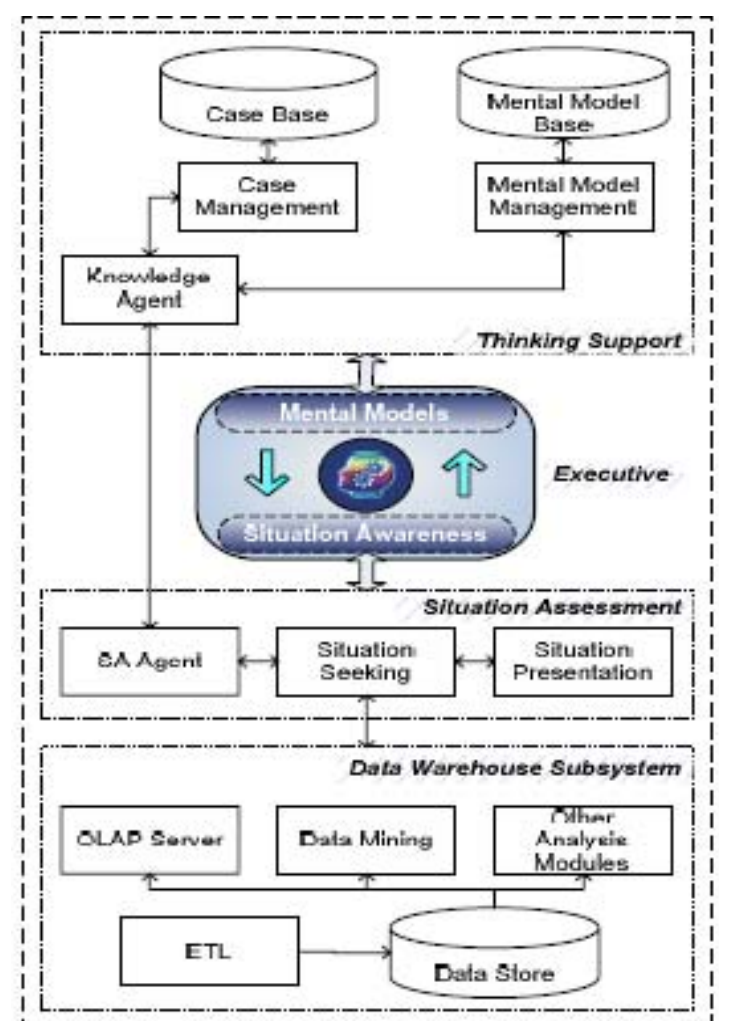

Fig. 3. Cognitive business intelligence systems [11]

Limitations: Although the researches [10], [11] highlighted the importance of BI in corporate community but have not discussed the non-BI factors affecting the widespread of BI in strategic decision making. The researches have discussed the importance of knowledge management integration, human-computer interaction, in traditional BI to make it more decision centric but failed to point out a road map to identify or incorporate non-BI factors into traditional BI applications. The researches [10], [11] have also come up with models, architectures for the purpose to align human-computer interaction while decision making. However the factors, other than knowledge management, having immense effect of intelligent decision making e.g. past experience, collective wisdom, socioeconomic effects, demographic trends and gut sense etc have not been discussed in the papers. The model [Fig. 2] presents a viable way out to human-computer interaction by offering multiple solutions of a given situation to the users. But it does not provide any insight to the knowledge management and to the non-BI factors spectrum. The model (Fig. 3) is a step forward to achieve real business intelligence and put forth the use of situational awareness on a given situation but does not cover the business specific non-BI factors. However, authors did not touch the area of other non-BI factors.

\section{A BI Model That Support Non-Bi Factors}

The increasing popularity of $\mathrm{BI}$ in corporate decision making also highlights shortcomings in traditional BI. Despite the improvements, BI still faces obstacles to its wide-spread success [3]. In order to make informed decisions on any given situation or strategy, data driven BI applications are not enough. True BI is hard to achieve until non-BI factors e.g. past experiences, demographic trends, socio-economic and cultural values along-with situational awareness and mental models involved in strategic decision making are not aligned in $\mathrm{BI}$ tools to help executives make smart decisions.

\section{A. Architecting Principles for Proposed BI Model}

The principle objectives of business intelligence that support non-BI factors can be summed up as follow:

- To provide a single version of truth across an entire organization.

- To timely deliver strategic, tactical and operational knowledge and actionable insight on a particular project initiative.

- To ensure that the delivered knowledge and actionable insights are well aligned with strategic business objectives and that the solution proposed by BI tool is mapped with the non-BI factors to achieve real BI.

\section{1) Executive: We have proposed a management decision centric (MDC) model for BI (Fig. 4).}

The objective of this model is to aid to the decision makers for decisions when encountered with a new project up-raising. The core suppositions of this model are that, confronted with a decision circumstances, the decision maker will run an information processing process underlined by situational awareness, knowledge need and non-BI factors information need.

This model was developed based on our latest work on 
identification of non-BI factors involved in strategic decision making [12].

\section{2) Salvage of situation}

Salvage of situation is the process of searching for knowledge base as well as other non-BI factors base information required for decision making. Salvage of situation is based on the executive's information and knowledge needs. Information need implies to what an executive needs to know for a given situation/problem that may heavily be extracted from non-BI base. Knowledge needs point the decision maker to the relevant knowledge base through reasoning process for situation understanding.

\section{3) Knowledge retrieval}

Knowledge retrieval is used to help the manager to remind the past experience pertaining to the current situation or newly proposed project for consideration. The past experience is re-used to form information needs in conjunction with the non-BI factor base.

\section{4) Information needs in-terms of Non-BI factors processing}

Information needs depict what information is needed for a realistic decision a particular situation, and how to acquire that information. In our model, situation information and business specific non-BI base is stored in the data warehouse, which can be accessed through DW queries. Hence it is reasonable to refer to data warehouse queries as the representation of information needs. Therefore, information need processing means building data warehouse queries.

\section{5) Situation retrieval and assessment}

The DW queries are sent to DW house for retrieving situation information. The retrieved situation information along with project specific non-BI factors is presented to the decision maker for situation assessment. The way we use to support situation assessment is knowledge-guided situation representation. Based on which, a graphical user interface (GUI) is used to present situation information to and receive feedback from the executive. The given feedback and lesson leant are then became the part of situation base and non-BI base.

\section{6) Decision generation}

Decisions are generated on the basis of the recognitionprimed decision (RPD) model [13]. Situation and non-BI factors assessment results in the manager's updated Situational Awareness. According to RPD theory, the user, at this stage, has a better opportunity to recognize the current decision situation and match it with similar past scenarios based on her/his SA and Experience [13]. However, the executive decision maker may want to go back to another iteration of decision cycle through reinputting the updated SA.

Situation recognition in light of the ground realities presented by non-BI analysis helps the executive recall decisions for past such project scenarios. The past decisions may then mentally examine and if found appropriate, past decisions might be adopted directly for current decision situation, or be revised accordingly. Finally, an appropriate decision is worked out. Decision making is also a wisdom process, during which the decision maker gradually accumulates field expertise. The non-BI and experience base will grow more reliable through constant intake of identification of new non-BI factors and new experience.

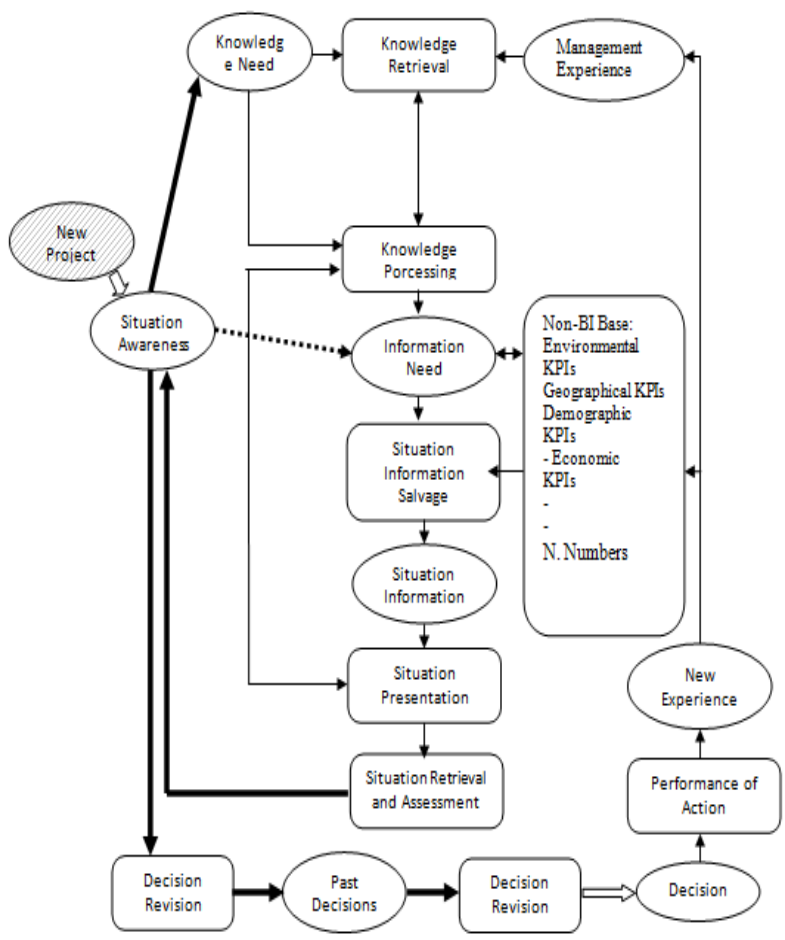

Fig. 4. Management decision centric (MDC) model for BI

When a decision situation is presented to the system,

The process starts from decision maker's initial SA about the situation as an input.

The model receives the $\mathrm{SA}$ input, retrieves case bas and non-BI base and parsed into information needs after integration.

The information needs are then used to retrieve DW house lookout the situation data which is then visualized and present to the executive.

The decision maker's decision process will finally update the KPIs of non-BI base and will make SA richer than the initial SA input.

\section{COMPARISON AND VALIDATION}

The proposed model is implemented, as a pilot activity, in Planning Commission to perform project upraising process. Planning Commission plays an integral role in the development of policy formulation in both Infrastructure and Social Sector. The primary function of Planning Commission is to act as a think-tank of the Pakistan in various arenas of social and economic development. It, being the apex planning body for the Government of Pakistan, holds the responsibility to forecast the effects and impacts of the development projects. Before authorizing any project, it is the responsibility of the Planning Commission to study the viability of proposed project and its need, keeping in view the scarce resources and financial constraints.

Whenever a new project is proposed, in a traditional system scenario, for up-raising/approval the project data is 
forwarded to the sectoral technical sections for different kind of analysis and viability (Fig. 5).

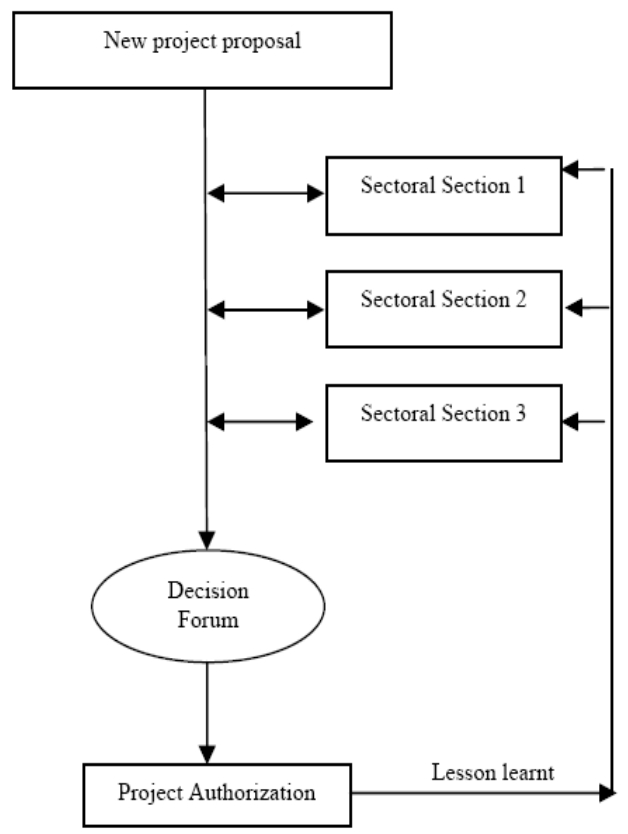

Fig. 5. Sect oral technical sections for different kind of analysis and viability

Viability of the proposed project with reference to economic and social perspective is checked by the sections. The technical sections are also responsible for performing analysis on pervious lesson base of the projects of the same nature and sector. Findings and recommendation regarding full approval, cancelation or conditional approval is presented to the decision making forum. Once the decision is made the lesson learnt during the analysis of the project are then send back to the concerned section for future reference made part of the lesson base.

The proposed model is also compared with the two models studied [10], [11] in context with knowledge support, situational awareness and non-BI factors incorporation (Table I).

TABLE I THe Proposed Model IS Also COMPARED With THE Two MODELS STUDIED

\begin{tabular}{|l|l|l|l|}
\hline $\begin{array}{l}\text { Comparison } \\
\text { factors }\end{array}$ & $\begin{array}{l}\text { Knowledge } \\
\text { based } \\
\text { model[10] }\end{array}$ & $\begin{array}{l}\text { Naturalistic } \\
\text { model } \\
{[11]}\end{array}$ & $\begin{array}{l}\text { BI model } \\
\text { supporting } \\
\text { non-BI factors }\end{array}$ \\
\hline $\begin{array}{l}\text { Knowledge } \\
\text { Support }\end{array}$ & Yes & Yes & Yes \\
\hline $\begin{array}{l}\text { Situational } \\
\text { support }\end{array}$ & No & Yes & Yes \\
\hline $\begin{array}{l}\text { non-BI factors } \\
\text { support }\end{array}$ & No & No & Yes \\
\hline
\end{tabular}

\section{CONCLUSION}

Computer does not stand out in solving unstructured problems, while decision making is also very risky if solely relying on human intuition. In order to make informed decisions on any given situation or strategy, data driven BI applications are not enough. No matter to what extent the BI application are made easy to use, easy to configure, cost effective; Real Business Intelligence can't be achieved until non-BI factors involved in strategic decision making are not aligned and modeled in BI tools to help executives make smart decisions.
This is a first step towards the realization of Real Business Intelligence which would align and bring more human-computer interaction. We proposed a non-BI factors based decision process model in this paper. Behind this model is our premise: processing of non-BI factors and retrieval for decision. The manager's are presented with non-BI data pertaining to a specific project and SA is analyzed to form knowledge needs. Non BI factors imply all such factors which are not taken care off but are extremely important while making GO decision for a project like: ground realities, socio-economic information, past experience, demographic information and knowledge of interest to perception and comprehension of decision situation. Non Bi factors, mental models, SA together with data warehouse metadata are used to form information needs and retrieved from data warehouse and presented to the executives. Situation information guided by non-BI factors analysis leads to the manager's richer SA, which opens the opportunity of feasible decisions.

\section{REFERENCES}

[1] Business Dictionary. [Online]. Available: http://www.businessdictionary.com/

[2] H. P. Luhn, "A business intelligence system," IBM Journal, 1958.

[3] G. Lawton, "Making business intelligence more useful," IEEE Computer Society, September, 2006.

[4] K. M. Sutcliffe and K. Weber, "The high cost of accurate knowledge," Harvard Business Review, 2003.

[5] L. Ou et al., "Knowledge and process based decision support in business intelligence," in Proc. First International Multi Symposiums on Computer and Computational Sciences, 2006.

[6] D. Linthicum, "Gartner reveals five business intelligence predictions for 2009 and beyond," 2009.

[7] H. J. Watson et al., "The current state of business intelligence," IEEE Computer Society, 2007.

[8] T. H. Davenport et al., Competing on analytics the new science of winning, Harvard Business School Press, 2007.

[9] L. Y. Wu et al., "A service-oriented architechure for business intelligence," in Proc. IEEE Conference on Service Oriented Computing and Applications (SOCA07), 2007.

[10] B. Azvine et al., "Real time business intelligence for adoptive enterprise," in Proc. 8th IEEE International Conference on ECommerce Technology, 2006.

[11] L. Niu et al., "An explorator cognitive business intelligence system," International Conference on Web Intelligence, 2007.

[12] M. I. Rafiq et al., "Business intelligence-Where do we stand," World Comp IKE USA, July, 2010.

[13] G. A. Klein, R. Calderwook, and D. Macgregor, "Critical decision method for eliciting knowledge," IEEE Transactions on Systems, Man, and Cybernetics - Part A: System and Humans, vol. 19, pp. 462-472, 1989.

Muhammad Irfan Rafiq is a seasoned IT, and project management professional with M.Phil degree in IT project management. He has been in service of public sector organizations of Pakistan since 2002. IT enablement, alignment of Information Technology processes with conventional means of project management in Pakistan is amongst one of his expertise. He has been involved in evolution of strategic paradigm shifts from traditional project preparation, management and documentation to IT enabled project management. He successfully conceived, documented and implemented BI framework that supports non-BI factors at Planning Commission, one of the apex project planning and monitoring organization of Pakistan. Currently the author is serving in Federal Tax Ombudsman of Pakistan in the capacity of Director IT projects.

Abid Farooq has received M.Phil degree in IT project management methodologies and currently serving in Federal Service Commission of Pakistan.

Muhammad Usman Mirza has received M.Phil degree in Business Process Re-Engineering and serving as Head of IT in a private bank of Pakistan. 